\title{
PROFITABILITY OF PAIRS TRADING STRATEGY IN FINLAND
}

\author{
John Paul Broussard - Mika Vaihekoski* \\ Work in process. Comments welcome.
}

November 24, 2010

\begin{abstract}
The profitability of self-financing pairs portfolio trading strategy (Gatev et al., 2006) is studied in the Finnish stock market under different weighting structures. Over the period 1987 to 2004, we find pairs trading to be profitable even after allowing for a one day delay in the trade initiation after the signal. On average, the annualized return can be as high as $15 \%$. The profits are not related to market risk. Fully invested pairs trading strategy is found to produce positive alpha during the sample period.

JEL-classification: G10, G11

Keywords: $\quad$ pairs, trading strategy, statistical arbitrage, short-selling, Finland, Helsinki Stock Exchange, Nasdaq OMXH
\end{abstract}

* Broussard: School of Business - Camden, Rutgers, the State University of New Jersey. Email: broussar(at)rutgers.edu. Vaihekoski: Turku School of Economics (TSE), Department of Accounting and Finance and Lappeenranta University of Technology (LUT), School of Business. Email: mika.vaihekoski(at)tse.fi. Latest version of the paper can be downloaded from http://users.utu.fi/moovai/. We are grateful for comments from Vesa Puttonen of Aalto University as well as Sofia Ramos and other participants of the Portuguese Finance Network $6^{\text {th }}$ Finance Conference, 2010 . 


\section{INTRODUCTION}

One of the popular trading strategies found in a statistical arbitrageur's toolbox is pairs trading. Not only is pairs trading a popular trading strategy, it is simple to implement. An arbitrageur finds two stocks whose prices move together over an indicated historical time period. If the pair prices deviate wide enough, the strategy calls for shorting the increasing-price security, while simultaneously buying the declining-price security. The idea behind the pair trade is to profit from convergence forces that eliminate short-term price deviations in favor of long-term historical pricing relationships. In a pricing world that is relatively efficient, simple strategies based on mean-reversion concepts should not generate consistent profits. Gatev, Goetzmann, and Rouwenhorst (2006), however, document pairs trading generates consistent arbitrage profits in the U.S. equity markets, which are considered the most efficient and liquid ones in the world.

Since the publication Gatev et al. (2006) surprisingly few studies have investigated pairs trading in markets other than that of the USA (one exception is Perlin, (2009) who evaluates pairs trading in Brazil). ${ }^{1}$ The purpose of this paper is to investigate the profitability of pairs trading in Finland, a stock market with much less liquidity than that found in the United States. Since the pairs trading strategy requires implementing two trades instead of one, evaluating performance in a less liquid market provides additional evidence regarding the strategy's global implementable efficacy.

There are two additional reasons why evaluating the pairs trading strategy in Finland is interesting. First, the time period evaluated, 1987 to 2004, covers not only the global boom and bust in the technology sector, but also the financial institution crisis of 1990 that impacted investors in Finnish equities. Evaluating the pairs trading strategy in such stressed market environments provides information to those evaluating the strategy's potential to act as a risk management alternative to traditional purely directional trading strategies. Secondly, a unique institutional characteristic regarding common and preferred shares in Finland allows a closer examination of potential causes for price deviation offered not only by similar securities, but by securities that have access to the same cash flow source.

1 This could be due to the computational complexity of estimating profits from the pairs trading despite the prima facie simplicity of the strategy. 
The results show the pairs trading strategy is persistently profitable even in a market with reduced liquidity. Significant profits are also generated by taking advantage of price deviations between common and preferred shares of the same firm. The latter result is important because one of the reasons suggested for profitable trading opportunities due to pair price deviation is trader risk aversion regarding fundamental value calculation uncertainty. If the trader's assessment of fundamental value is highly uncertain, then prices may deviate persistently because trades made to take advantage of mispricing are not undertaken. Trader risk aversion, therefore, potentially reduces the profit potential of the pairs trading strategy because lack of trading activity may allow nonconvergence of disequilibrium asset prices. The finding that profits can be made from price deviation between assets with claims on the same cash flow source provides additional support for this naïve investment trading strategy. ${ }^{2}$

The remainder of this paper is organized as follows. Section 2 provides a brief introduction to the pairs trading strategy as well as the estimation strategy employed in this paper. Section 3 presents the data and Finnish institutional characteristics. Section 4 shows the empirical results. Section 5 concludes and offers some suggestions for future research.

\section{PAIRS TRADING INVESTMENT STRATEGY}

\subsection{Pairs methodology}

Similar to Gatev et al. (2006), our implementation of the pairs trading strategy proceeds in two stages. First, pairs of stocks are selected for trading using a twelve month period of data, termed the formation period. Second, trades are made on the pairs during the six months following the formation period if trading conditions are met. The six month trading horizon is called the trading period. Only

\footnotetext{
${ }^{2}$ In addition, one can also view pairs trading as an enhanced index strategy (sometimes called index plus) where an index manager aims to beat the benchmark by taking small active bets on the underlying positions. In this framework, the pairs strategy corresponds to a situation where the manager over-weights some stocks (the long position in the pair) and under-weights others (the short position in the pair). If the pairs strategy is profitable, he/she should beat the benchmark.
} 
stocks that are listed throughout the 18 month period are included in the analysis. ${ }^{3}$ Using the stocks that are traded throughout the 18 month period, one finds first those pairs of stocks that show similar behavior. As an alternative to using co-integration as a measure of similarity, we compare normalized price series of all selected stocks against each other. The pairs that are selected for trading have the smallest distance measure, which is defined as the sum of squared deviations between the two normalized price series. Normalized price series are defined to start from one, and then evolve using the return series. False trading signals due to splits or dividends are avoided by using total return series to construct the series in the manner similar to Gatev et al.

Once the chosen number of pairs of stock series has been found, the question is whether one can trade profitability on them during the trading period. The trading strategy is based on the idea that if the prices diverge, there is a profit to be made because the prices are expected to converge sooner or later. In practice, the pair is opened if a trading signal is observed. A positive trading is indicated if pairs' normalized prices diverge more than two times the standard deviation of the price differences during the formation period. ${ }^{4}$ The trade is opened by buying the stock with lower normalized price, and selling (short) the higher priced equity. The long-short transactions are effected to yield a net position of zero. Thus, the trade is considered self-financed. The pair trade is then closed by reversing the opening transactions once the normalized prices cross the two-standard deviation threshold. If a pair remains open at the end of the trading period, it is closed whether or not price convergence occurred.

To calculate the return for a pair of stocks over the whole trading period, one needs to accumulate weighted daily returns from the long and short positions. To get daily value-weighted returns for a pair, we use the following equation

$$
r_{p t}=w_{1 t} r_{t}^{L}-w_{2 t} r_{t}^{S}
$$

3 This produces a small forward looking bias as we only analyze stocks that are listed throughout the formation and trading periods. Gatev et al. exclude stocks with one or more days without trade. They do not, however, comment whether or not they used the same look-ahead condition.

4 Note that it is also possible that a pair is not opened at all during the trading period. 
where weights $w_{1 t}$ and $w_{2 t}$ are initially assumed to be one after which they change according to the changes in the value of the stocks, i.e., $w_{i t}=w_{i t-1}\left(1+r_{i t-1}\right)$. Gatev et al. used the following equation ${ }^{5}$

$$
r_{p t}=\frac{\sum_{i \in p} w_{i t} r_{i t}}{\sum_{i \in p} w_{i t}}
$$

which basically gives the same result if the weights are adjusted accordingly. ${ }^{6}$

Using the return series for each pair, we can calculate the return for a portfolio of the two securities. Following Gatev et al. we use two different weighting schemes. The first weighting scheme is called the committed capital scheme, which essentially commits equal amounts of capital to each one of the pairs. If the pair is not opened or it is closed during the trading period, the capital is still committed to the pair. Whereas Gatev et al. assumed risk-free rate of return for non-open pairs, we assume zero return for the sake of cautiousness. In our second and main approach, we utilize a fully invested weighting scheme. The fully invested scheme is less conservative as it assumes capital is always divided between the pairs that are open.

However, contrary to Gatev et al., we utilize two different approaches to changes in the weights in both schemes. The first one is basically similar to theirs. ${ }^{7}$ Namely, the (unweighted) sum of returns are divided either by the estimated number of pairs (here: five) or the number of pairs that are open (at any given day) for the committed capital and fully invested weighting scheme, respectively. We label this as the equally weighted approach as it implicitly assumes that each of the (open) pairs is given the same weight at any given time. Although computationally convenient, it requires in practice frequent trading to keep the weights in balance which raises costs.

5 Note that there was a minor typographical error in the denominator of equation (2) in Gatev et al. (2006) as $w_{i t}$ was included in the subscript of the sum.

6 Note that the concept of rate of return on a zero net capital is somewhat problematic and hence no standardized method is available. In the literature, the return has been typically calculated either on the long leg of the position, the margin capital needed to undertake the short position, or on the gross capital exposure. The approach used here (equation 1) implicitly takes into account the gross exposure.

7 Gatev et al. (2006) are a bit vague in describing their weighting approach. Our best interpretation is that they have used equation (2) as we have used equation (1), and for a portfolio of pairs they have used what we have labeled as equally weighted approach. 
Our second approach, labeled as value-weighted approach, utilizes equation (2) to calculate relative weights for each pair where weights for each pair follows $w_{p t}=w_{p t-1}\left(1+r_{p t-1}\right)$ with a starting value of one. In practice, we assume that each pair is given the same weight at the beginning of the trading period. If a pair is not opened, the return is zero, and thus the weight does not change. This implies that for the fully invested weighting scheme, the money from a closed pair is invested in the other pairs that are open (according to their relative shares). If a pair is re-opened, the money is invested back by redistributing the investment between the pairs according to their relative weights, i.e., $w_{p t}$ divided by the sum of the weights. Similarly, if a pair is not opened until later in the trading period, the weight will be one in absolute terms (as for others), but in relative terms the weight has likely changed.

Once one has recorded the returns from the trading period, the sample period is rolled forward and the estimation is redone with the latest set of data. Gatev et al. rolls the time period forward by one month, which allows for parallel formation and trading pairs every month (up to six times the chosen number of pairs). As a result, their technique potentially allows for one stock to be selected in more than one pair (possibly even on opposite sides of the trade). Although this parallel rolling selection technique may be suitable in a marketplace with a vast array of stocks available, a sequential selection approach is more suitable in a marketplace where the number of stocks is limited, as is the case in Finland. As a result, our implementation differs slightly from theirs in that the time horizon of formation and trading periods are rolled forward by six months, instead of on a monthly calendar. Specifically, the pairs are formed using data either for January to December within a calendar year, or from July to June the following year. In addition, the quantity of evaluated pairs is restricted to be five in this paper, whereas Gatev et al. also evaluate the strategy using higher number of pairs, up to 20.

\subsection{Case Finland}

Finland is one of the Nordic countries that showed high economic growth after the Second World War. As with many other countries around the world, the last couple of decades have been a period of extremely high growth both in terms of economic activity and financial markets. There are, 
however, several features that differentiate Finland from other countries, especially the US, during the sample period analyzed in this paper, 1987-2004.

First, the Finnish stock market (established in 1912) was in many ways underdeveloped and segmented from international markets until the 1990s. The first steps in the integration process were taken in the early 1980s, e.g., when foreign interest in Finnish stocks started to increase. As a result, foreigners started to buy Finnish stocks, which led the government to restrict foreign ownership to 20 percent (later raised to 40 percent) of the total equity. The shares that the company made available to all investors (including Finnish investors) were labeled as unrestricted. Those that only available to Finnish investors were labeled as restricted stocks. Both instruments were traded and priced separately by the stock exchange from 1984 forward. Unrestricted stocks traded typically with a premium to the restricted ones.

Even though allowed before the 1980s, Finnish companies also started to issue in increasing numbers preference shares - a second equity class instrument, which had lower voting rights than common stocks, but often carried a higher dividend payment. These stocks were often also available in unrestricted and restricted versions. As a result, some companies (e.g., Nokia) had as many as four listed stock instruments (common and preference, both available as restricted and unrestricted). However, the restrictions on foreign ownership were abolished from the beginning of 1993 and the number of listed stock series was cut almost by half (see Vaihekoski, 2004, for details). In addition to removing the ownership restrictions, the government also removed the one percent of the value tax levied on all trades (i.e., stamp duty) conducted on the stock exchange in an effort to increase onexchange trading.

Second, liquidity in the Finnish stock market was fairly low, especially in the early 1990s due to the economic crisis as well as the multiple stock series listed. This low level of liquidity generates a substantially thinly-traded market, which is evidenced by low trading volumes and high bid-ask spreads. At times, the value-weighted spread across all stocks listed in the stock exchange was close to ten percent (see Vaihekoski, 2009). Towards the end of the sample period, the spread started to decrease, and ultimately in early 2000s, was even less than one percent. 
A third differentiating fact that directly relates to the efficacy of pairs trading profitability in Finland is connected to the time span short-selling was officially allowed in the Finnish stock market. Shortselling officially began at the Finnish stock exchange in 1995 when Suomen Optiomeklarit Ltd (SOM; which later merged with the stock exchange) started trading LEX-short-selling instruments. These instruments are formed by combining two zero-priced forward contracts, one of which matures immediately and the other within the next nine months. The quoted price for the contracts was the premium paid by the buyer to the seller. ${ }^{8}$ In addition, the buyer provided collateral to the exchange (typically $125 \%$ of the value of the loan), which acted as the counterparty between both sides of the trade. These instruments were available for the most liquid stocks. However, the trading was partly hurt by the stamp duty set on the transactions and the unfavorable tax treatment of the dividends for those lending the stocks. The legislation was changed in 1997 favoring the official organized trading as the stamp duty on OTC-trades remained if the loan was for more than ten trades (later changed in 2007). HEX set up a lending pool to facilitate lending of the stocks in year 2000 and further enhancements were made later in April 2004. After the merger of the HEX and OM, the trading of LEX-instruments was moved to Stockholm in 2005, where short selling trading takes places under the name "Finnish Stock Loan".

Even though the official Finnish short selling time history is much shorter compared to that found in the US market, one has to keep in mind that short-selling could also take place as an OTC-trade between two parties.' It was also fairly common that within a bank, different departments of the bank could loan stocks back and forth from other departments. In addition, some contemporary commentators estimated that approximately 70-90 percent of the short selling on Finnish securities took place abroad (see Korhonen, 2000). ${ }^{10}$ In addition, a number of loans took place through the clearing system, especially in the cases of stock delivery failure.

Finally, from an economic perspective, Finland suffered an extremely severe economic crisis in the early 1990s. GDP growth was negative for a number of years beginning late 1990 and lasting until late 1993 (see Figure 1). There are several reasons behind this uncommonly deep recession. First,

8 The premium was at first typically between one to two per cent of the value but later the premium levels dropped due to increased number of transactions and automatization. In the USA, the premiums are typically less than one percent (source needed).

9 Short-selling in the U.S. began in the early $20^{\text {th }}$ century (Burke and Martello, 1997).

10 The number of LEX-contracts traded at the HEX increased from 154,952 in 1996 to 2,004,210 in 2001. 
Finnish interest rates were unusually high before the crises began. Policy makers decided to set high interest rates in order to defend the Finnish currency against devaluation pressures. Ultimately, the currency was allowed to float in the middle of the crisis in September 1991. Second, the Finnish banking sector experienced a severe crisis of its own due to lax lending policies and unpreparedness for the structural changes sweeping the industry in the late 1980s and early 1990s. Third, the collapse of the Russian Empire resulted in a vast reduction in Finnish exports. After the recession, however, the growth in the economy has been especially strong. One company in particular, Nokia, has been credited with the economic turnaround.

\section{DATA}

We use daily data for Finland from the beginning of 1987 to the end of 2004. All stocks listed in the Official List (later Main List) of the Nasdaq OMX Helsinki Stock Exchange (OMXH) during the sample period are used in the analysis. ${ }^{11}$ The number of stocks listed on the OMXH varied between 100 and 150 during the sample period. Since the number of available series is limited, no stocks are excluded from the study due to thin trading. Stock returns are calculated from the daily closing prices and they are adjusted for the dividends, issues, and splits (i.e. returns are in effect total returns). ${ }^{12}$

In addition to the stock returns, we use daily stock prices to identify whether or not a stock is listed throughout the 18 month period. Finally, we utilize monthly risk-free rates of returns as well as return on the market portfolio in the analysis. Monthly risk-free rates of return are generated by the monthly holding period returns calculated from one month Helibor (prior to 1998) and Euribor rates (from the beginning of 1998) as suggested in Vaihekoski (2009). The return on the market portfolio is the return on the value-weighted stock market index for the HSE. The Finnish stock market returns from 1991 forward are calculated using the value-weighted OMXH yield index (previously HEX index) calculated by the stock exchange. Prior to 1991, we use the WI-index which is calculated

11 Prior to October 1998, a number of stocks were also quoted on the OTC and the Brokers' Lists. The list structure was renewed into Main List, I List and NM List. At the same time the number of companies listed on the Main List increased from 80 to 91 . The trading and the market values of the companies traded on I and NM Lists was small compared to that of the Main List (e.g., in 1996: the trading was 0.8, 1.0, and 101 billion FIM for the Brokers', OTC, and Official Lists, respectively. See Vaihekoski (1997) for more information.

12 Prior to 1991, the returns are calculated from the average mid-day price quotations. Data was provided by the Department of Finance and Statistics, Hanken School of Economics. 
by Berglund et al. (1983). ${ }^{13}$ All returns are measured as percentage returns. All monthly returns are measures from month-end to month-end.

\section{EMPIRICAL RESULTS}

\subsection{Main results}

Table 1 shows descriptive statistics for the monthly percentage returns for the TOP 5 pairs trading strategies under two different weighting schemas. Monthly returns are calculated using daily cumulative return indices. The TOP 5 pairs are chosen to be those with the smallest distance measure. Panel A lists the results for the investment scenario allowing same-day investment of the pair as indicated by the distance measure. Panel B lists the results for the investment scenario that allows for a one-day waiting period prior to investment of the various pairs. The reason for evaluating the pairs in a one-day lag is to allow for potential delays with implementing the trade after seeing the trading signal. In addition, it allows one to form a more conservative view on the profitability as the lag allows for one to take into account potential difficulties in executing the trade as well as the effect of bid-ask spread in the market.

As indicated in Table 1, the monthly returns are positive and significantly different from zero across portfolio formation measures when the pair can be initiated same day. All but one month is positive when the one day lag approach is evaluated. As expected the results in Panel A are superior to those in Panel B, indicating the importance of rapid execution of the trade. Similarly, the more conservative, committed capital approach shows lower returns than the fully invested approach. The fully invested approach yields typically twice the return or more of the committed capital approach, albeit with higher volatility.

In Panel A, the average return on the equally weighted fully invested pairs portfolio is 4.465 percent which is clearly higher than of what Gatev et al. found for their portfolio (1.308\%). On the other hand, after allowing for the one day waiting period, the average drops to 1.171 percent, which is

13 The WI-index has been frequently used to augment the HEX-index in previous studies. For more details on the indices, see Nyberg and Vaihekoski (2010). 
higher but closer to that found in Gatev et al. (0.745\%). The higher return result is consistent with an explanation that wider wide bid-ask spreads and thinner trading on the Finnish stock market. Both characteristics can cause sudden price changes in the recorded closing prices, which may be reversed the next day.

The maximum monthly return from the pairs trading is surprisingly large (e.g., 30.48\% and 69.37\%) for committed capital and fully invested schema with equal weighting on pairs, respectively, when compared to Gatev et al. (14.72\% in the case of committed capital). As a result, we decided to analyze this particular value in more detail. The high return was achieved in April 1990 which took place during a trading period that started in January and ended in June 1990. In four out of the five pairs the stocks selected for trading are multiple classes of stocks (MIT A restricted and unrestricted, Yhtyneet Paperitehtaat ordinary and preference, Wärtsilä I restricted and unrestricted, Fiskars K restricted and unrestricted). Only one pair consisted of stocks from two different companies (Unitas $\mathrm{B}$ and Kymmene). Figure 2 shows the indexed price development for the pair of Yhtyneet Paperitehtaat (currently known as UPM) stocks during this period and whether the pair is open or closed. This pair was the best performer of the five pairs returning a little over 100 percent during April 1990 alone. This indicates that the multiple stock series, in theory, have provided an excellent opportunity for pairs trading. ${ }^{14}$

However, one should be cautious on analyzing the results with instant execution on the signal without a waiting day as the liquidity is likely to be thin. The average returns from the more realistic trading approach, which requires for one day waiting period, suggests an annualized return of 14.99 percent, which is a bit higher than what Gatev et al. found in the US market $(9.31 \%)$. The results confirm the profitability of the pairs trading strategy and suggest that there appears to be substantial profit opportunity for using the pairs trading strategy even in a low liquidity providing environment such as that found in Finland.

Figure 3 shows the monthly returns from the fully invested equally weighted portfolio of pairs under one day waiting rule. We can use the figure to check for outliers and overall behavior of the strategy.

14 We also calculated returns from a pairs trading strategy, where weights on both sides of the pair were kept equal (i.e., $\mathrm{w}_{1 \mathrm{t}}$ and $\mathrm{w}_{2 \mathrm{t}}$ were constants in equation 1). In practice, this means that the manager sells (long or short) the stock that has generated more returns (or equivalently, buys more that one that has returned less). This obviously generates costs, but on the other hand, it could be justified by the fact that this keeps the portfolio net-zero investment throughout the investment period or by the fact that the weight on short-side of the pair cannot exceed 100 percent. 
One can clearly see that there are few months with extremely positive returns. As a robustness check, we analyze the extremes in more detail. The first one takes place in April 1990. In four out of five pairs, the pair consists of two different stock series of a company's stock (i.e. ordinary vs. preference or unrestricted vs. restricted). The results are rechecked, and found to exist in the data. Possibly, these particular results are a manifestation of traders profiting on short-term opportunities arising from sudden deviations in the series' prices.

Table 2 lists additional details on the trades of portfolios formed with a one day lag after the trading signal. Altogether 502 pairs were opened over the time horizon evaluated. Over the 17 year sample period, there are 34 trading periods. There are 11 periods when one of the a priori best pairs did not end up being opened at all.

The average price deviation trigger for opening the pairs was 0.0693 (the prices are scaled to being from a unity value of 1). The average number of times a pair is opened in any 6-month time period is less than 15 (14.76), and each pair is held open a little less than 23 days (22.73) on average. Each pair also exhibited being traded, in a round-trip fashion, almost three times (2.95) every six months. This indicates pairs were opened and closed approximately 3 times every six months.

When one adds the data presented in Table 2 to that shown in Table 1, the indication is that not only does pairs trading generate significantly positive profits, the transactions required to generate those profits do not appear to be very frequent. Although the average holding period per pair is not indicative of a long-term "buy and hold" strategy, the frequency of transactions, as well as their commensurate costs, appears low. This low turnover of the pairs trading strategy, however, may be due to the low liquidity in the Finnish Market, which may induce a spurious stability of the strategy. Figure 4, however, indicates the long-term opportunities inherent in the pairs trading strategy.

\subsection{CAPM-tests and subperiod analysis}

Finding positive returns using a self-financing trading strategy raises the question whether the returns can be explained solely by the risk taken. To answer this question, we test the CAPM model against the returns to see if the returns are driven by the strategy's exposure to market risk. The results from 
the excess return market model regression are reported in Table 3 together with Sharpe ratios and other statistics. Note that all return series here are in excess of the risk-free rate of return.

Panels A-C show alphas and betas together with their t-values as well as adjusted R-squares from the OLS regression estimation using the full sample period and two subperiods. The standard errors have been adjusted for heteroscedasticity and autocorrelation using Newey-West with four lags. The results clearly show that the returns are not driven by the market risk. The beta is not found significant in any of the cases at the five percent significance level. This means that the pairs strategy has been market neutral, which is often a desirable property for many hedge funds strategies.

Analyzing the subperiods, one can see that the latter time period appears more profitable. All Sharpe ratios, as well as Jensen's alphas, are positive, although not statistically significant. This is somewhat surprising as it appears the strategy is potentially generating higher profits over time. If the efficiency of the Finnish Stock market has improved, as is the case with improved liquidity, lower spreads, and easier short-selling during the second sub-period, one would expect profit opportunities to decrease.

\subsection{Robustness checks}

We also conducted a number of additional analysis and tests. First, we analyzed the stocks selected for the pairs trading in more detail. The results (not reported) are consistent with our expectation that more than half of the pairs are formed between different series or stock classes of a company's equity. Second, we analyzed the effect of weighting approach within a pair on the results. Using equal weights for long and short positions in each pair throughout the trading period, which corresponds to a net zero capital position did not qualitatively change the results.

Finally, we study whether the profits are driven by the lack of liquidity in the Finnish market. In practice, we estimate the results in Table 1 again under the additional constraint that a pair can be opened only if the trading volume is higher than zero when the pair is opened. The results under the one day waiting rule before implementing the trade show the average annualized return for equally weighted strategies are 2.916 and 9.034 percent (vs. 6.524 and 14.989) for committed capital and fully invested portfolios, respectively. The latter value is still statistically significantly different from zero (at ten percent level with t-value equal to 1.90). Both averages are clearly lower than those observed 
in Panel B, but overall they show that the returns from the pairs trading are significant even after accounting for the infrequent trading.

\section{CONCLUSIONS}

In this paper, we reviewed the pairs trading strategy approach presented in Gatev et al. (2006) and discussed its implementation. We evaluated the profit-generating potential of the strategy on the Finnish stock market. Combined with the fact that the Finnish stock market is more inefficient and many companies listed in Finland have multiple stock series offering potential for pairs trading, one may expect ex ante to observe potentially high returns from the strategy. On the other hand, the relatively illiquid characteristic of the Finnish stock market may reduce profit potential by impeding strategy implementation.

The pairs trading strategy was tested using a sample period of seventeen years from 1988 to 2004. The results show that the pairs strategy produces statistically significantly positive returns during the sample period. The results confirm the finding of Gatev et al. that pairs trading is indeed a profitably strategy, and not specific to the US market. The returns also do not appear to be driven by the systematic market risk factor.

Although the results of this paper indicate high returns to pairs trading are possible, there may be implementation problems that could cause lower than expected returns if the strategy is actually put into practice. Additionally, the multiple share class environment exhibited in Finland may generate higher returns than those in markets where only single classes are traded. However, the evidence indicates that trading multiple share classes may provide pairs trading profit opportunities in other markets that exhibit similar institutional characteristics.

The analysis in this paper uses data that ends in 2004, which is two years after that used in Gatev et al. Extension of the dataset, a more concentrated effort to detangle the effects of multiple stock series, as well as an additional evaluation of thin trading and transaction costs are left for future research. 


\section{REFERENCES}

Bris, A., Goetzmann, W. N., Zhu, N., 2007. Efficiency and the Bear: Short-Sales and Markets Around the World, The Journal of Finance, 62(3), 1029-1079.

Burke, K., Martello, G., 1997. The evolution of securities lending. In Fabozzi, F. J. (ed.): Securities lending and repurchase agreements. USA: Frank J. Fabozzi Associates.

Elliott, R. J., Van Der Hoek, J., Malcolm, W. P., 2005. Pairs trading. Quantitative Finance, 5(3), 271276.

Gatev, E., Goetzmann, W. N., Rouwenhorst, K. G., 2006. Pairs Trading: Performance of a RelativeValue Arbitrage Rule. The Review of Financial Studies, 19(3), 797-827.

Korhonen, H., 2000. Arvopaperilainaus. University of Helsinki. Unpublished manuscript. Availalable on the internet. URN:NBN:fi-fe20001116

Nyberg, P., Vaihekoski, M., 2010. A new value-weighted index for the Finnish stock market. Forthcoming in Research in International Business and Finance, 2010. doi: 10.1016/j.ribaf.2009.12.006

Perlin, M., 2009. Evaluation of pairs-trading strategy at the Brazilian financial market. Journal of Derivatives \& Hedge Funds, 15(2), 122-136.

Vaihekoski, M., 2009. Pricing of Liquidity Risk. Empirical Evidence from Finland. Applied Financial Economics, 19(19), 1547-1557.

Vaihekoski, M., 2004. Portfolio Construction for Tests of Asset Pricing Models. Financial Markets, Institutions \& Instruments, 2004, 13(1), 1-39.

Vaihekoski, M., 1997. The Finnish stock market: Recent trends and important events. The Finnish Journal of Business Economics, 46(4), 526-543. 


\section{Table 1. Excess (net) returns of pairs trading strategies}

Summary statistics for the monthly percentage excess (net) returns on portfolios of top five pairs between 1988 and 2004. Four different weighting schemes have been used. Equally weighted scheme divides the sum of portfolios returns either by the five (committed capital) or by the number of pairs open each day (fully invested). Value-weighting scheme takes into account the development of the weights during the trading period. In Panel $\mathrm{B}$, one day waiting period before executing on the pairs-signal is assumed.

\begin{tabular}{|c|c|c|c|c|}
\hline & \multicolumn{4}{|c|}{ TOP 5} \\
\hline & \multicolumn{2}{|c|}{ Equally weighted } & \multicolumn{2}{|c|}{ Value-weighted } \\
\hline & committed cap & fully invested & committed cap & fully invested \\
\hline \multicolumn{5}{|l|}{ Panel A: No waiting } \\
\hline Average excess return & 0.02213 & 0.04465 & 0.02313 & 0.04695 \\
\hline Standard error & 0.00327 & 0.00685 & 0.00378 & 0.00791 \\
\hline$t$-statistic & 6.77 & 6.52 & 6.12 & 5.94 \\
\hline \multicolumn{5}{|l|}{ Excess return distribution } \\
\hline Median & 0.0206 & 0.0278 & 0.0202 & 0.0263 \\
\hline Standard deviation & 0.0467 & 0.0978 & 0.0540 & 0.1129 \\
\hline Skewness & 2.1147 & 3.3105 & 3.3727 & 4.4700 \\
\hline Excess kurtosis & 10.3555 & 17.7647 & 21.1395 & 31.1740 \\
\hline Minimum & -0.0851 & -0.1058 & -0.0846 & -0.1145 \\
\hline Maximum & 0.3048 & 0.6937 & 0.4374 & 1.0143 \\
\hline Share of negative observations & $28.9 \%$ & $30.9 \%$ & $29.9 \%$ & $30.9 \%$ \\
\hline \multicolumn{5}{|l|}{ Panel B: One day waiting } \\
\hline Average excess return & 0.00528 & 0.01171 & 0.00374 & 0.00999 \\
\hline Standard error & 0.00217 & 0.00451 & 0.00225 & 0.00402 \\
\hline$t$-statistic & 2.44 & 2.59 & 1.67 & 2.48 \\
\hline \multicolumn{5}{|l|}{ Excess return distribution } \\
\hline Median & 0.0032 & 0.0063 & 0.0023 & 0.0075 \\
\hline Standard deviation & 0.0309 & 0.0645 & 0.0321 & 0.0574 \\
\hline Skewness & 0.1639 & 2.1106 & 0.5890 & 0.8411 \\
\hline Excess kurtosis & 2.0276 & 11.8617 & 2.9228 & 2.8237 \\
\hline Minimum & -0.0980 & -0.1216 & -0.0907 & -0.1312 \\
\hline Maximum & 0.1239 & 0.4441 & 0.1413 & 0.2744 \\
\hline Share of negative observations & $41.2 \%$ & $45.1 \%$ & $44.6 \%$ & $43.1 \%$ \\
\hline
\end{tabular}




\section{Table 2. Trading statistics with one day waiting lag}

Trading statistics for portfolio of top five pairs formed with one day lag. Average price deviation trigger for opening a pair is calculated as the price difference divided by the average of the prices.

Top 5

Total number of pairs opened 502

Periods when at least one pairs opened (out of max)

Average price deviation trigger for opening pairs 0.0693

Average number of pairs opened per six-month period

14.7647

Average number of round-trip trades per pair in months where at least one pair opened

Average number of round-trip trades per pair

2.9529

Standard deviation

Conditional on at least one pair opened

3.1573

Average time pairs are open in trading days

22.7311

Standard deviation

34.4367 


\section{Table 3. Market risk of pairs trading strategies}

The market risk exposure of the excess percentage monthly returns of TOP5 portfolios based on pairs trading strategy under the one day waiting rule is tested. Three different weighting schemes have been used to create the portfolios. All returns are in excess of one month risk-free rate. Market portfolio is proxied by the Finnish stock market index. In panel A, the full sample from 1988 and 2004 is used to calculated profits. In panels B and C, two subsamples have been used. T-values are provided in parenthesis. Standard errors used to calculate t-values are adjusted for autocorrelation $($ lags $=4)$ and heteroscedasticity using Newey-West method. Coefficients significant at the five percent level are marked with an asterisk $(*)$.

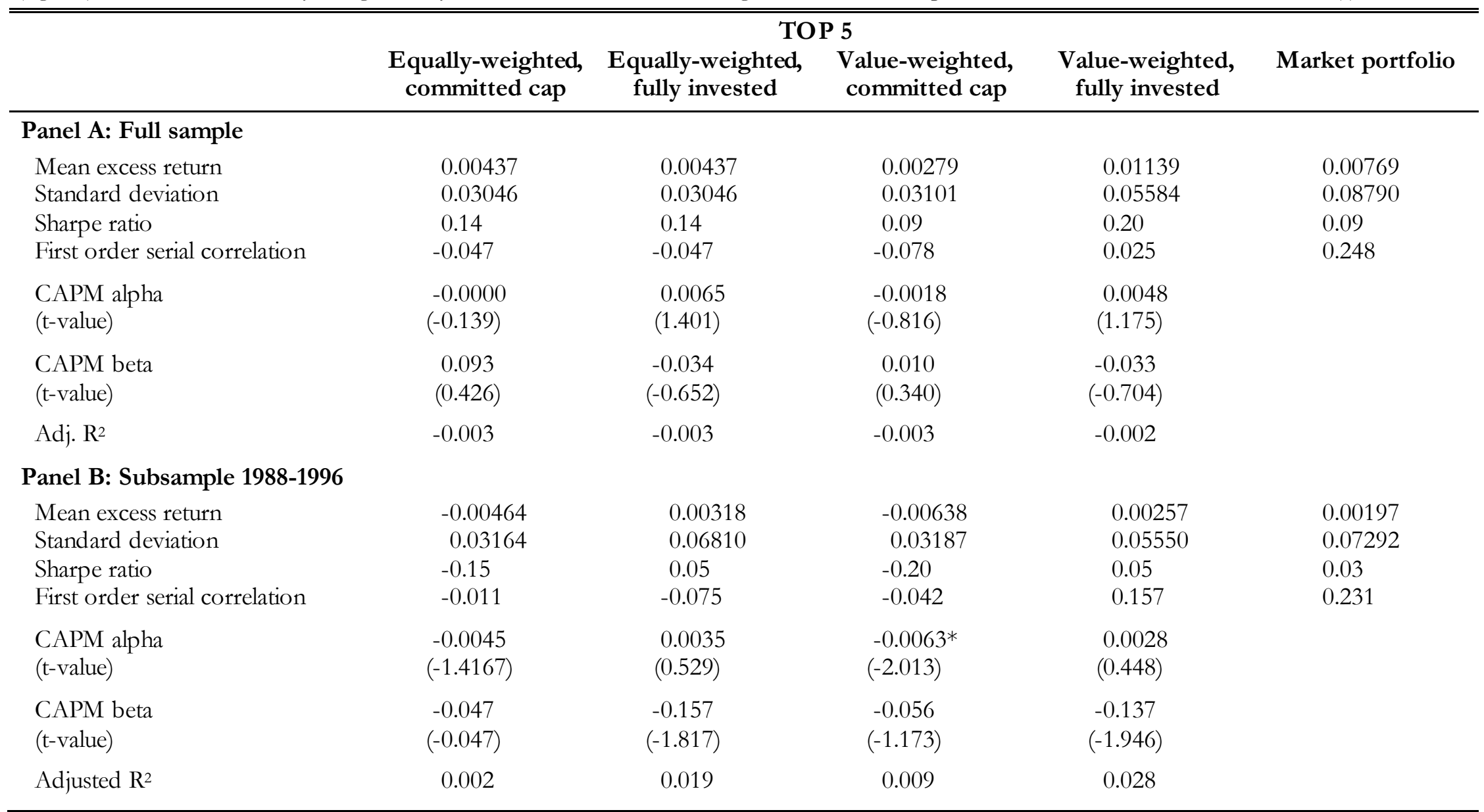


Table 3. Continued

\begin{tabular}{|c|c|c|c|c|c|}
\hline \multicolumn{6}{|c|}{ Panel C: Subsample 1997-2004 } \\
\hline Mean excess return & 0.00478 & 0.00964 & 0.00347 & 0.00668 & 0.01413 \\
\hline Standard deviation & 0.02999 & 0.06004 & 0.03214 & 0.05912 & 0.10215 \\
\hline Sharpe ratio & 0.16 & 0.16 & 0.11 & 0.11 & 0.14 \\
\hline First order serial correlation & -0.088 & -0.044 & -0.078 & -0.057 & 0.251 \\
\hline $\begin{array}{l}\text { CAPM alpha } \\
\text { (t-value) }\end{array}$ & $\begin{array}{c}0.0042 \\
(1.320)\end{array}$ & $\begin{array}{l}0.0092 \\
(1.470)\end{array}$ & $\begin{array}{c}0.0028 \\
(0.838)\end{array}$ & $\begin{array}{l}0.0063 \\
(1.044)\end{array}$ & \\
\hline $\begin{array}{l}\text { CAPM beta } \\
\text { ( } \mathrm{t} \text {-value) }\end{array}$ & $\begin{array}{c}0.041 \\
(1.229)\end{array}$ & $\begin{array}{c}0.032 \\
(0.546)\end{array}$ & $\begin{array}{c}0.042 \\
(1.154)\end{array}$ & $\begin{array}{c}0.024 \\
(0.401)\end{array}$ & \\
\hline Adjusted $\mathrm{R}^{2}$ & 0.009 & -0.008 & 0.007 & -0.009 & \\
\hline
\end{tabular}




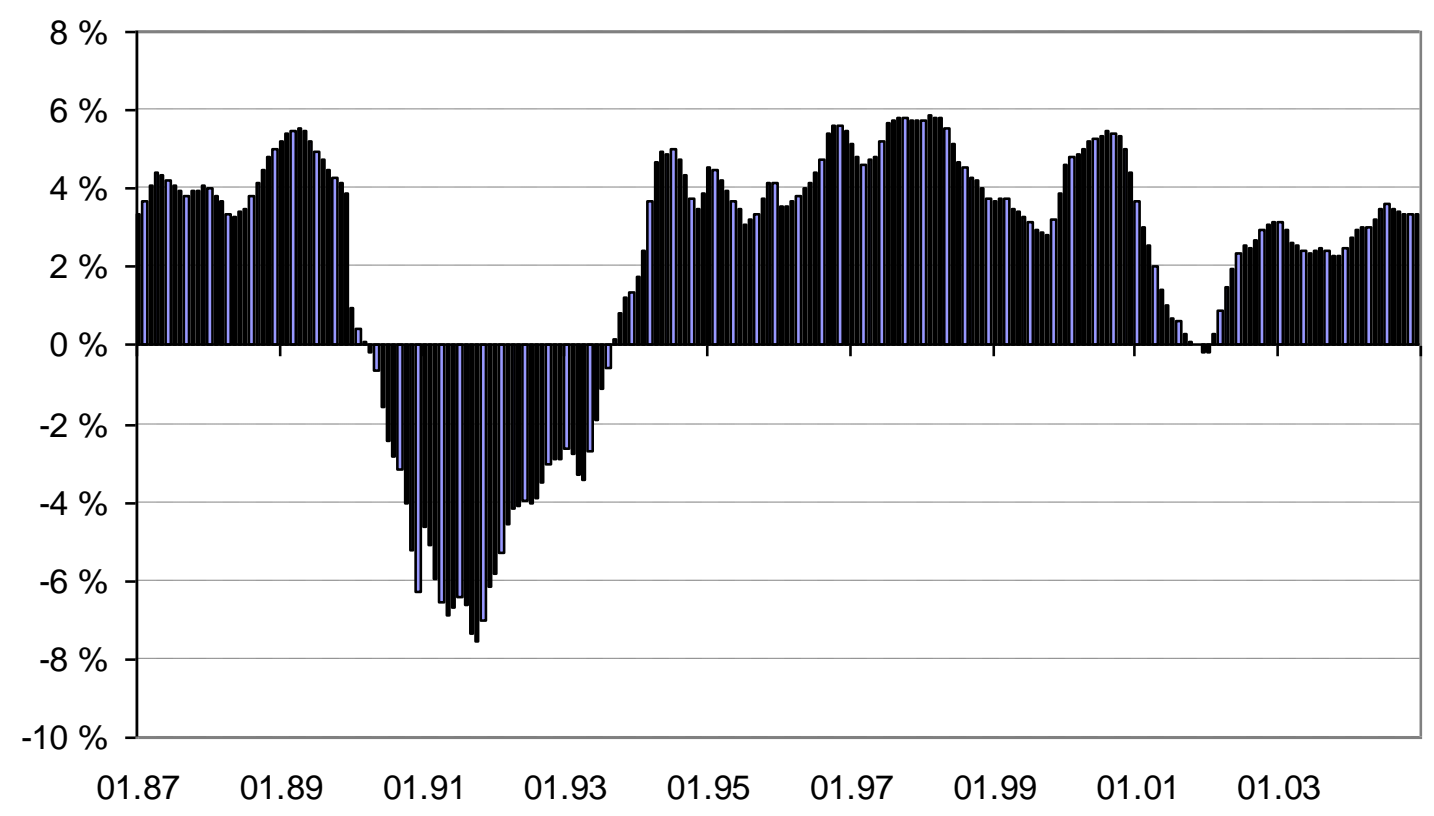

Figure 1. Year-on-year change in the Finnish GDP.

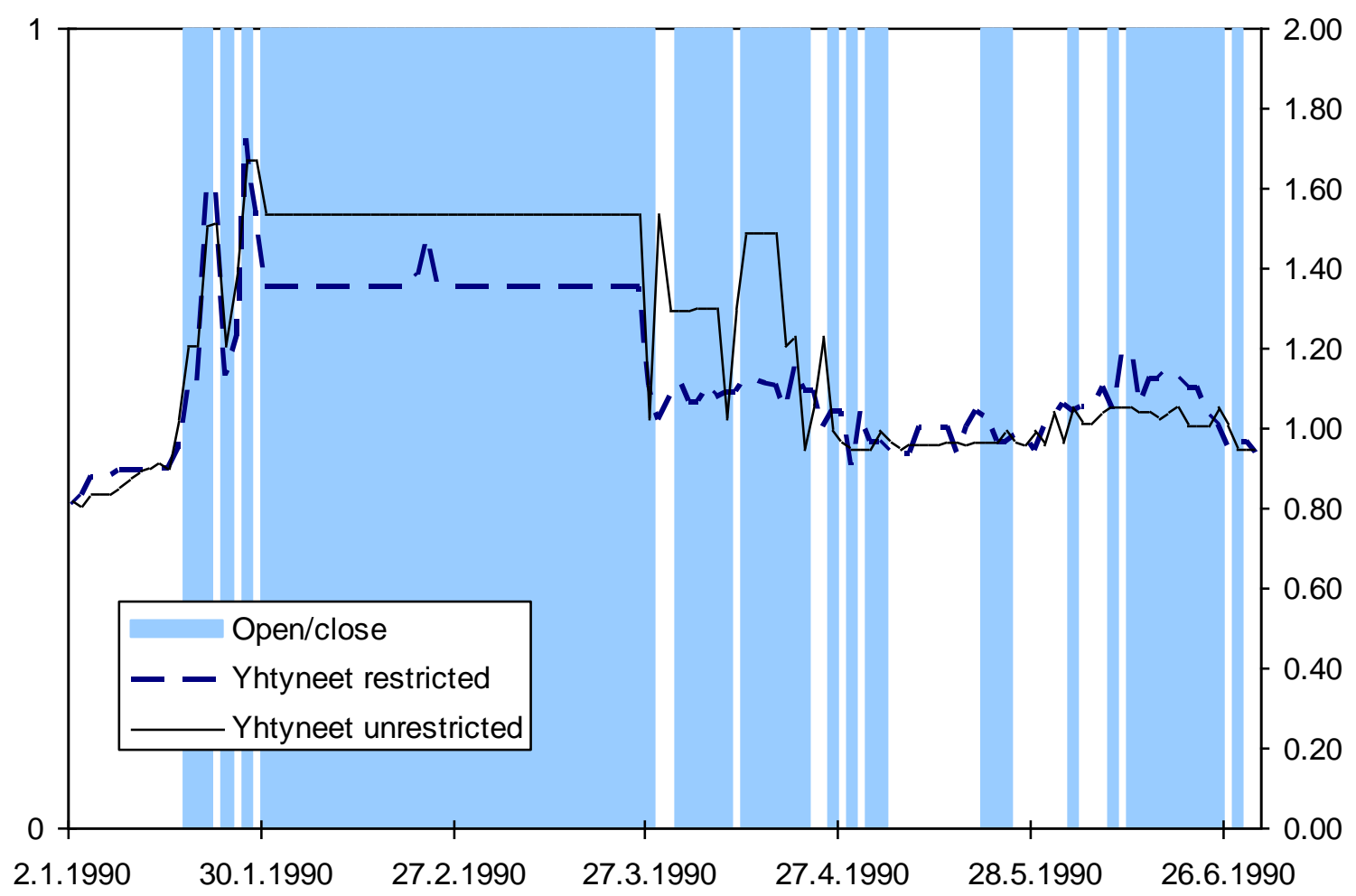

Figure 2. Example of pairs trading during Jan-June 1990. 


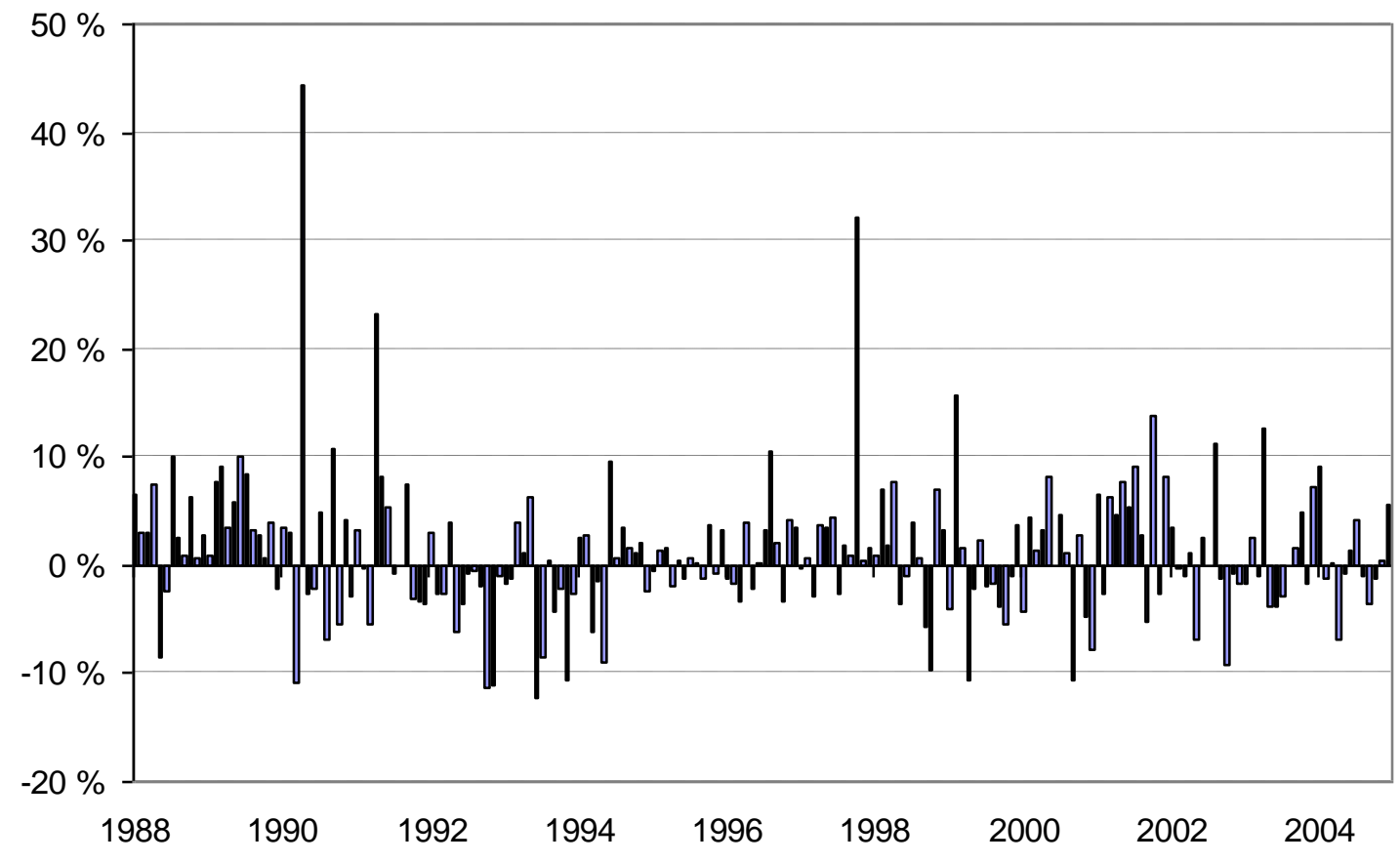

Figure 3. Monthly excess percentage returns of top 5 pairs portfolios during 1988-2004. Returns are calculated for the equally weighted fully invested portfolios (i.e. investment is always equally divided to open pairs). 


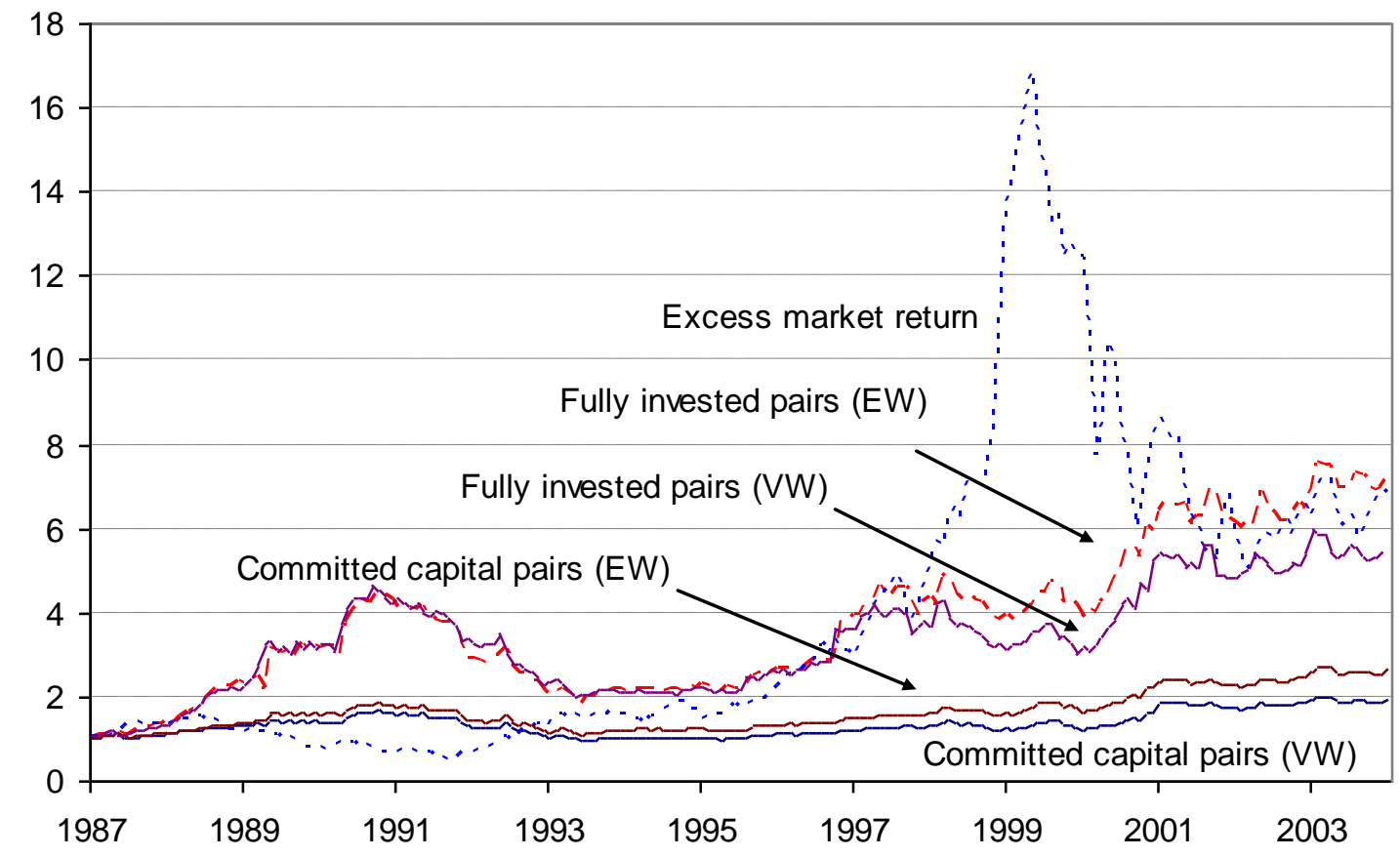

Figure 4. Cumulative monthly return indices of top 5 pairs (fully invested and committed capital with equal and value-weighting), and market returns in excess of risk-free rate of return. 